OPEN ACCESS

Edited by:

Paul D. Loprinzi,

University of Mississippi,

United States

Reviewed by:

Simone Di Plinio,

Università degli Studi "G. d'Annunzio"

Chieti - Pescara, Italy

Abiodun E. Akinwuntan, University of Kansas Medical Center

United States

*Correspondence:

Andrew P. Smith

SmithAP@Cardiff.ac.uk

Specialty section:

This article was submitted to

Cognitive Science,

a section of the journal

Frontiers in Psychology

Received: 02 May 2020

Accepted: 20 August 2020 Published: 11 September 2020

Citation:

Fan J and Smith AP (2020) Effects of Occupational Fatigue on Cognitive Performance of Staff From a Train

Operating Company: A Field Study.

Front. Psychol. 11:558520.

doi: 10.3389/fpsyg.2020.558520

\section{Effects of Occupational Fatigue on Cognitive Performance of Staff From a Train Operating Company: A Field Study}

\author{
Jialin Fan ${ }^{1,2}$ and Andrew P. Smith ${ }^{2 *}$ \\ ${ }^{1}$ School of Psychology, Shenzhen University, Shenzhen, China, ${ }^{2}$ Centre for Occupational and Health Psychology, School \\ of Psychology, Cardiff University, Cardiff, United Kingdom
}

Background: Occupational fatigue is a key issue in the rail industry that can endanger staff, passenger, and train safety. There is a need to demonstrate the relationship between workload, fatigue, and performance among rail staff.

Objective: The present study, conducted in the workplace in realistic situations, integrating both subjective and objective measurements, aimed at demonstrating the relationship between workload, fatigue, and cognitive performance with a rail staff sample.

Methods: The "After-Effect" technique was applied in the current study. Online diaries and cognitive performance tasks were used to assess the fatigue, work experiences, and performance of rail staff before and after work on the first and last days of one working week.

Results: Reported fatigue was greater after work on both the first and last day of the working week. There were large individual differences in the change in fatigue and workload ratings. Analysis of covariance with age and the pre-work performance score as covariates and the post-work performance score as the dependent variable showed that high levels of fatigue were associated with impaired performance on both the visual search and logical reasoning tasks. Workload had fewer effects on performance than fatigue.

Conclusion: This field study provided evidence for the relationship between workrelated fatigue and performance impairment. The findings show the need for future work on predicting fatigue-related performance decrements, and the necessity of providing interventions and support so that the risk to safety can be reduced.

Keywords: occupational fatigue, rail industry, rail staff, field study, performance

\section{INTRODUCTION}

Fatigue is often an indicator of an unhealthy lifestyle. It has found to be associated with higher probability of illness and injury in the workplace (Harma et al., 1998, 2002; Chau et al., 2008). Fatigue is synonymous with a generalized stress response over time. Occupational fatigue may occur during or after work; it may also occur before work when the worker has not fully 
recovered from previous fatigue through the regular periods of rest before the onset of the next set of demands (Cameron, 1973). It has been found to be associated with impaired cognitive performance, including increased reaction time, decreased vigilance, perceptual and cognitive distortions (reviewed in Krueger, 1989), dropped skill effectiveness (Drew, 1940). Fatigue also leads to impaired memory and information processing (Craig and Cooper, 1992), reductions in concentration, motivation, and activity (Beurskens et al., 2000). In addition, fatigue may impair the sense of agency (i.e., the loss of the sense of being responsible for own's actions; Howard et al., 2016), which increases the safety risks in the workplace. In particular, previous studies show that human agency was reduced by increased out of the loop events which could be associated with fatigue, and decreased control or increased automation in the environment (Berberian et al., 2012; Kumar and Srinivasan, 2012, 2013; Moore, 2016; Di Plinio et al., 2019, 2020). Such effects may also show inter-individual differences (Di Plinio et al., 2019) and also vary with cultural background (Barlas and Obhi, 2014).

In the railway industry, occupational fatigue is a severe problem which jeopardizes not only the staff health but also train and passenger safety, as most jobs are safety-critical. Evidence for fatigue among rail staff has been found in previous studies, in which various methods have been used, including surveys (Cotrim et al., 2017; Fan and Smith, 2017), incident reports (reviewed in Buck and Lamonde, 1993; Ugajin, 1999; Fan and Smith, 2018), simulated driving studies (Dorrian et al., 2007), and interviews (Filtness and Naweed, 2017). In particular, fatigue is considered to be a causal or contributory factor in the majority of train accident and incident investigation reports (British Rail Safety and Standards Board, 2005; British Rail Accident Investigation Branch, 2008, 2010). Fatigue, its impact on task performance, and fatigue-related human errors have been found in previous research in several different transport sectors (e.g., road drivers: Feyer and Williamson, 2001; seafarers: Smith et al., 2006), and has also been suggested as a key issue for train safety (Bowler and Gibbon, 2015). However, the field of rail fatigue research was historically smaller than that of other transport sectors, and the investigation of the effect of fatigue on performance in real time in the workplace is still lacking in this industry.

The causes of occupational fatigue can emanate from either inside or outside the workplace, and mainly include task-related factors and sleep-related factors. Jobs in the rail industry were designed to operate on a $24 / 7$ basis, often with an irregular schedule. A large-scale study (Fan and Smith, 2017) identified the main predictors of fatigue in the rail industry as high job demands (i.e., workload), shift-work, poor job control and support, and noise and vibration in the working environment. Shift work, especially the night and early morning shifts, disrupts the sleepwake cycle (Ferguson et al., 2008) and deprives workers of sleep (Åkerstedt, 1991). Shift workers have little time to recover when working certain shift hours, which makes them more likely to suffer from cumulative fatigue (Åhsberg et al., 2000). Moreover, Dorrian et al. (2011) indicated that in addition to work hours and sleep length, workload significantly influenced fatigue among train crew. It is notable that mental workload is the major problem in the modern railway industry rather than traditional physical workload, due to the increasing level of automation in operating systems (Young et al., 2015; Fan and Smith, 2019). The majority of job tasks in this modern industry require more cognitive demands (e.g., selective attention, sustained vigilance), resulting in a heavy mental workload and increased fatigue; meanwhile, fatigue is associated with a deterioration of attention and impaired performance. Failure to maintain such performance at an acceptable level brings danger, especially to those working in safety-critical job roles.

Subjective measurement of fatigue has been validated as a reliable way to distinguish between fatigued and non-fatigued staff (e.g., Chalder et al., 1993; Kim et al., 2010), and this is widely used in different types of job disciplines, both within (Kishida, 1991) and between industries (Kogi et al., 1970; Beurskens et al., 2000). Recently, however, Cheng and Hui-Ning (2019) argued that the ability of rail staff to perceive their own fatigue could be limited, which may due to sleep debt and cumulative sleep loss, particularly following a string of atypical shifts (night or early morning shift). Therefore, it is important to also include objective measurement of fatigue and performance which can be used in the work situation along with subjective measurement to reducing potential subjective biases. However, it can be a challenge to apply certain objective measurements in the railway environment. Railway companies usually have their own rules regarding staff uniforms for consistency and safety, which means that wearing extra instruments for objective measurement, such as Electroencephalography (EEG) or eye-tracking equipment, is not allowed in the workplace, as it may cause distractions and other potential safety risks.

Broadbent (1979) suggested that using the "After-Effect" technique in fatigue measurement could be applicable in realistic situations. This involves measuring performance before and after a specific task or work period, without changing people's normal behaviors during and after the task. The after-effect symptoms of fatigue usually include longer reaction times and reduced accuracy. In the work context, the After-Effect method compares the difference in performance before and after work, and a greater difference reflects a greater effect. This method has already been widely used in workload studies (e.g., Parkes, 1995; Hockey and Earle, 2006). For instance, workload study Parkes's (1995) found that reaction time and accuracy in search tasks and logical reasoning ability showed clear impairments due to the effect of higher workload. It has also been used to assess other factors which contribute to fatigue, such as the common cold (Smith et al., 2000), caffeine (Brice and Smith, 2001; Smith, 2002; Doherty and Smith, 2005), and night work (Åkerstedt, 1988). Recently, Smith and Smith (2017) used the After-Effect method to assess rail engineers' fatigue and performance on the first and last day of the work week and showed that the extent of fatigue could be identified using this methodology.

Online fatigue measures could be a more appropriate tool for detecting fatigue in the workplace due to their convenience and low development cost. Online cognitive tests have been used for the past two decades, and a review of them confirmed their ability to provide realistic simulations of cognitive tasks in daily life, which is the main advantage of computerized 
cognitive evaluation (see Crook et al., 2009). It is possible for online measures to be used in the workplace and they are often more convenient than offline tests or the use of measures from laboratory experiments. One fatigue study with students, which used a methodology that combined the After-Effect method and online cognitive performance tasks to measure fatigue in a reallife setting (Fan and Smith, 2017), established the relationship between workload, fatigue, and cognitive performance. This study showed that workload increased subjective fatigue after work which then resulted in cognitive performance impairments, including slower reaction time and decreased accuracy, while the effect of time of day on performance was not found significant. However, this study consisted of undergraduate students with risk factors for fatigue due to their study life at university, which are different from fatigue in the actual work life of the railway industry. Thus, a further experiment based on a staff sample is needed.

The present study aimed to use this same methodology to demonstrate the relationship between workload, fatigue, and objective performance with staff from a train operating company. The company was interested in generic fatigue across a range of jobs. Other research has adopted the present approach to study train drivers (Evans, 2019), conductors, guards, and engineers (Smith and Smith, 2017). The methods used in this study consisted of a self-assessment diary, mainly used to record ratings of fatigue and workload, and also objective performance tests. The experimental hypothesis for this study predicted that an increased feeling of fatigue would lead to performance reduction, including delayed reaction time, and lower accuracy rates in both visual search and logical reasoning tests. This methodology was also used to examine whether the effects of fatigue and workload were different.

\section{MATERIALS AND METHODS}

\section{Participants}

This study recruited participants with different types of jobs from volunteers from a train company in the United Kingdom $[N=19$, mean $( \pm \mathrm{SD})$ age $=41.86 \pm 9.89$ yrs.; $74 \%$ male], as all job types may be susceptible to fatigue (Fan and Smith, 2017). The main job types reported were managers, conductors, drivers, station workers, engineers, and administrators. Selection of different job types meant that any obtained results could be generalized across occupations. Participants were fit for work but no other data was collected on health status.

\section{Procedure}

This study included four sessions in total, requiring participants to complete the diary and the tests immediately before starting work, and immediately after finishing work on the first and fourth days of a working week. For example, if one participant was off-work on Tuesday and Wednesday, and then worked the following four continuous days, this participants would complete the diary on Thursday (the first day of his or her working week) and on Sunday (the last day of his or her working week). An invitation e-mail with attached information about the study and an informed consent form was sent to potential participants. Once participants had signed and returned the forms, they were asked to provide the start date of their next work week with four continuous days of working. The links to the four test sections and a familiarization session were then sent to them. The familiarization session included an introduction to the diary and an example of each cognitive task to ensure that the participants were able to complete the tasks correctly before starting the study. On the testing day(s), participants were asked to complete the online diary and cognitive tasks immediately before starting work and immediately after finishing work via a computer or mobile phone.

Participants were free to withdraw from the survey at any point. This study was reviewed and approved by the School of Psychology Research Ethics Committee at Cardiff University and carried out with the informed consent of the volunteers.

\section{Materials}

The materials used in this study included a diary and two online cognitive tasks and took about $15 \mathrm{~min}$ to complete. These online measures required assessment by mobile phone or computer, and participants responded by touching the screen (if using mobile phone) or clicking on the mouse (if using the computer). All the tasks and data collection were via the Qualtrics online survey platform.

\section{Diary}

The diary was used to measure fatigue and the causes of fatigue. It consisted of 15 single-item questions, including six questions to be answered before work and nine questions to be answered after work. Supplementary Table 1 (in Supplementary Material) shows the details of the diary questionnaire. It was designed based on the material used in Smith and Smith's (2017) diary studies, and majority questions were on a 10-point scale. The questions in the pre-work diary covered sleep duration and quality, commute time, fatigue due to the commute, general health status, and alertness before starting work. The questions in the post-work diary recorded workload, effort, fatigue, stress, break duration, work duration, time of work completion, and level of distraction during work. There were extra questions in the post-work diary on the last day, which asked whether the participants had worked at the same time every workday during the working week; if participants answered no, they were asked about their working time for each day.

\section{Online Cognitive Tasks}

Two online cognitive tasks were used to assess objective performance in each session: a visual search and a logical reasoning task. These two tests have been widely used in previous workload (e.g., Parkes, 1995) and fatigue studies (e.g., Lamond and Dawson, 1999; Barker and Nussbaum, 2011). The online version of such tests was validated in our previous study with the student sample (Fan and Smith, 2017; Fan, 2019). Supplementary Figures 1, 2 (in Supplementary Material) shows the example of a trial of each task. For both tasks, the inter-trial intervals were $500 \mathrm{~ms}$. The tasks were distributed and the data collection was completed via the Qualtrics online survey platform. Participant 
would assess the task using either computer or mobile phone, responding by clicking mouse or tapping touch screen.

The visual search task consisted of 12 trials, which randomly appeared from a total of 30 possible trials. In each trial, participants were randomly shown a 60-letter set and one target letter. They were required to find and click the target letter as quickly and accurately as possible on the screen. The response time and accuracy for each trial were recorded.

The logical reasoning task consisted of 24 trials and required the participants to make a decision between two options as quickly and accurately as possible. This test was based on Baddeley's (1968) grammatical reasoning test. The outcome measures were response time and accuracy.

\section{ANALYSIS}

Both the diary and the cognitive tasks were presented online using the Qualtrics software package. The diary and performance data were then downloaded into a single SPSS data file. Analysis was carried out using the IBM SPSS 25 package. The main focus of the analysis was on the associations between fatigue and workload and changes in performance over the day. Analyses of covariance with the pre-work measures and age as covariates, and the post-work performance scores as dependent variables were carried out. Fatigue and workload change scores were split into high and low groups (based on the median of scores from these questions in the diary) and these were the between subject factors in the analyses of covariance. Fan and Smith (2017), in a study of university students, found that fatigue reduced visual search accuracy and led to slower logical reasoning speed. Workload had no significant effects. One-tail significance levels were used where the two tailed level was not significant, as it was predicted that high fatigue and high workload would be associated with impaired performance seen in the Fan and Smith (2017) study.

\section{RESULTS}

\section{The Sample}

Nineteen participants, 14 of whom were male, completed the whole study. The most common job types reported were managers $(26.3 \%)$, engineers $(15.8 \%)$, conductors $(15.8 \%)$, drivers (15.8\%), and station workers (15.8\%), followed by administrators (10.5\%). Most participants did daytime shifts (68.4\%), while $31.6 \%$ did night shifts (begin between the hours of 7:00 p.m. and 12:00 a.m.) or early morning shifts (begin between the hours of 12:00 a.m. and 6:00 a.m.). Nearly half (43.1\%) of the participants worked two or more different shift times during the testing week (4 days).

\section{Fatigue and Workload Ratings}

The descriptive statistics for the fatigue ratings and the performance tasks, are shown for pre-work and post work on the first and last day of the working week in Table $\mathbf{1}$.

On the first working day, fatigue ratings showed a large increase over the day (pre-work mean $=2.16$; post-work mean $=6.42$ ). There was considerable variation across individuals with the increase in fatigue having a range from 0 to $800 \%$. A similar profile was seen for the last working day (pre-work mean: 2.47; post-work mean $=7.11$ ), and again there were large individual differences in the change of fatigue over the day (range $=-14-900 \%)$. Workload ratings were consistent across days $($ Day $1:$ mean $=5.79, \mathrm{SD}=2.18$; Day $4:$ mean $=5.42$, $\mathrm{SD}=2.43$ ) and showed large individual differences (Day 1: range $=1-9$; Day 4: range $=1-9$ ).

Changes in fatigue over the day were correlated with age (Day 1: $r=0.73, p<0.001)$. On the last day increased fatigue was associated with greater distraction due to thinking about other things $(r=0.49, p<0.05)$. Workload ratings were associated with ratings of effort $(r=0.61, p<0.01)$, stress $(r=0.49$, $p<0.05)$, and alertness $(r=-0.49)$. These results show that fatigue and workload are different constructs which are only weakly correlated.

\section{Changes in Fatigue, Workload and Performance Changes Over the Day}

Analyses of covariance were carried out to examine associations between changes in fatigue, workload and performance after work. Changes of fatigue and workload were divided into high and low groups using a median split. Before work performance measures were covariates for the corresponding after work measure (the dependent variable). Age was also included as a covariate. It was predicted that increases of fatigue and workload would be associated with impaired performance.

On the first day, the high fatigue group had less accurate performance on the visual search task than the low fatigue group $(F=3.78, \mathrm{df}=1.13, p=0.037,1$-tail, partial eta squared $=0.225)$. This result is shown in Figure 1.

Also on Day 1, the high workload group had less accurate performance on the logical reasoning task than the low workload group $(F=5.37, \mathrm{df}=1,13, p=0.037$, partial eta squared $=0.292)$. This result is shown in Figure 2. None of the other effects were significant.

On the last working day, the high fatigue group again had less accurate performance on the visual search task $(F=5.84$, $\mathrm{df}=1,13, p=-0.031$, partial eta squared $=0.310)$. This is shown in Figure 3.

The high fatigue group were also slower than the low fatigue group on the logical reasoning task on the last day $(F=3.38$, $\mathrm{df}=1,13, p<0.045,1$-tail, partial eta squared $=0.206)$. This is shown in Figure 4.

\section{DISCUSSION}

The present research involved a field study using online fatigue tests integrating both subjective and objective measurements, which was validated in a previous fatigue study (Fan and Smith, 2017). The design of the fatigue tests combined online methods and the After-Effect technique. This methodology was suitable and convenient to use in the workplace, especially in the railway industry where wearing 
TABLE 1 | Descriptive statistics for fatigue ratings and performance tests (mean [SD]).

\begin{tabular}{lcccc}
\hline & Day 1 Pre-work & Day 1 Post-work & Day 4 Pre-work & Day 4 Post-work \\
\hline Fatigue ratings (scale of 1-10; high scores = greater fatigue) & $2.16[1.21]$ & $6.42[2.12]$ & $2.47[1.61]$ & $7.11[2.00]$ \\
Visual search accuracy (\% correct) & $97.81[4.68]$ & $97.81[4.68]$ & $94.07[5.77]$ & $90.35[8.45]$ \\
Visual search speed (s) & $13.58[3.15]$ & $14.25[3.00]$ & $13.93[3.54]$ & $14.29[3.06]$ \\
Logical reasoning accuracy (\% correct) & $74.34[20.00]$ & $77.63[21.35]$ & $74.78[22.27]$ & $79.39[23.63]$ \\
Logical reasoning speed (s) & $6.28[1.73]$ & $6.94[2.39]$ & $5.58[1.40]$ & $5.66[1.38]$
\end{tabular}

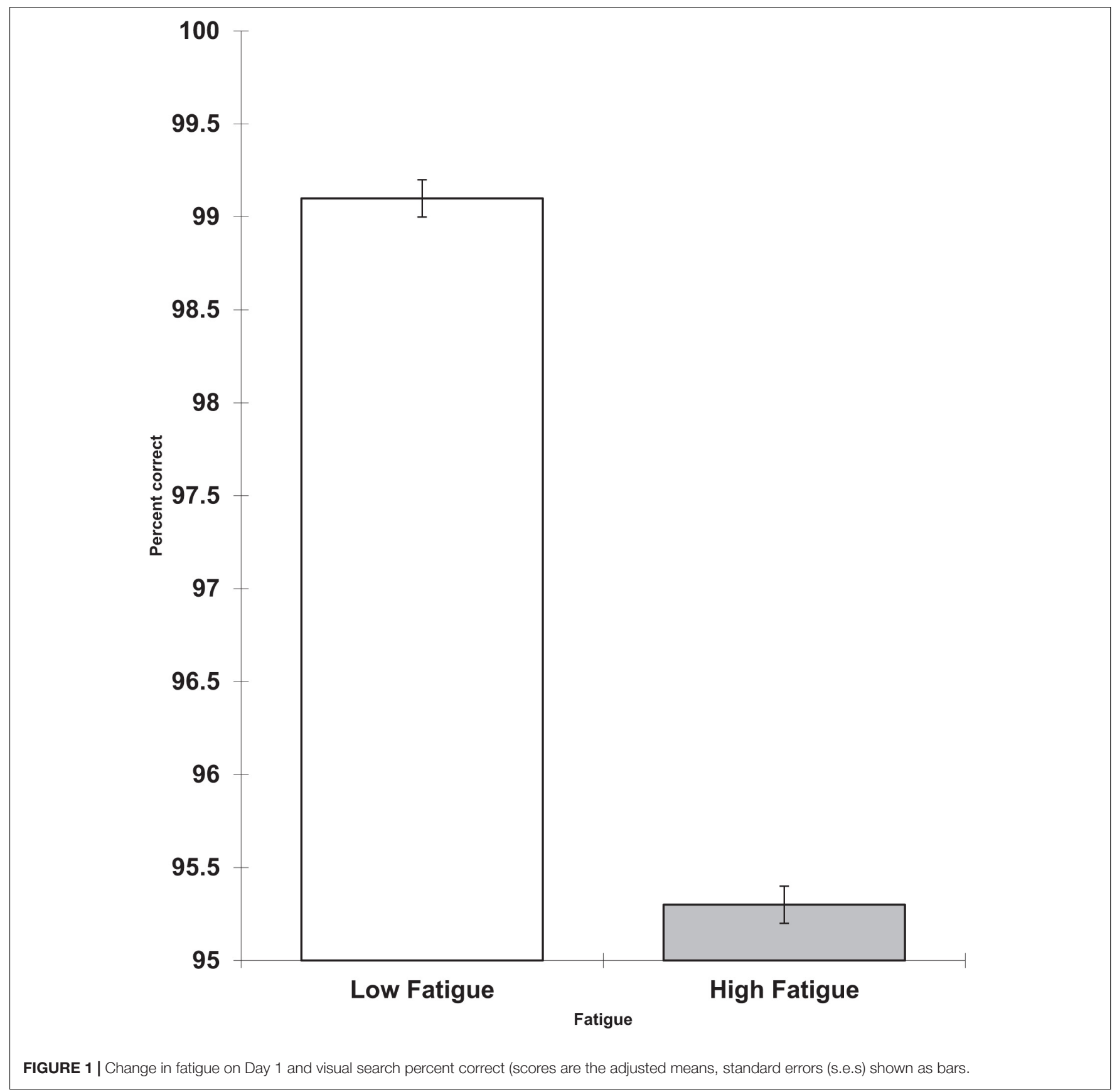

extra instruments of objective measurement was not allowed, as this might create distractions and pose other potential safety risks.
Overall, the results of this study with the staff sample were in line with those of previous studies, including our study with a student sample using the same performance tasks 


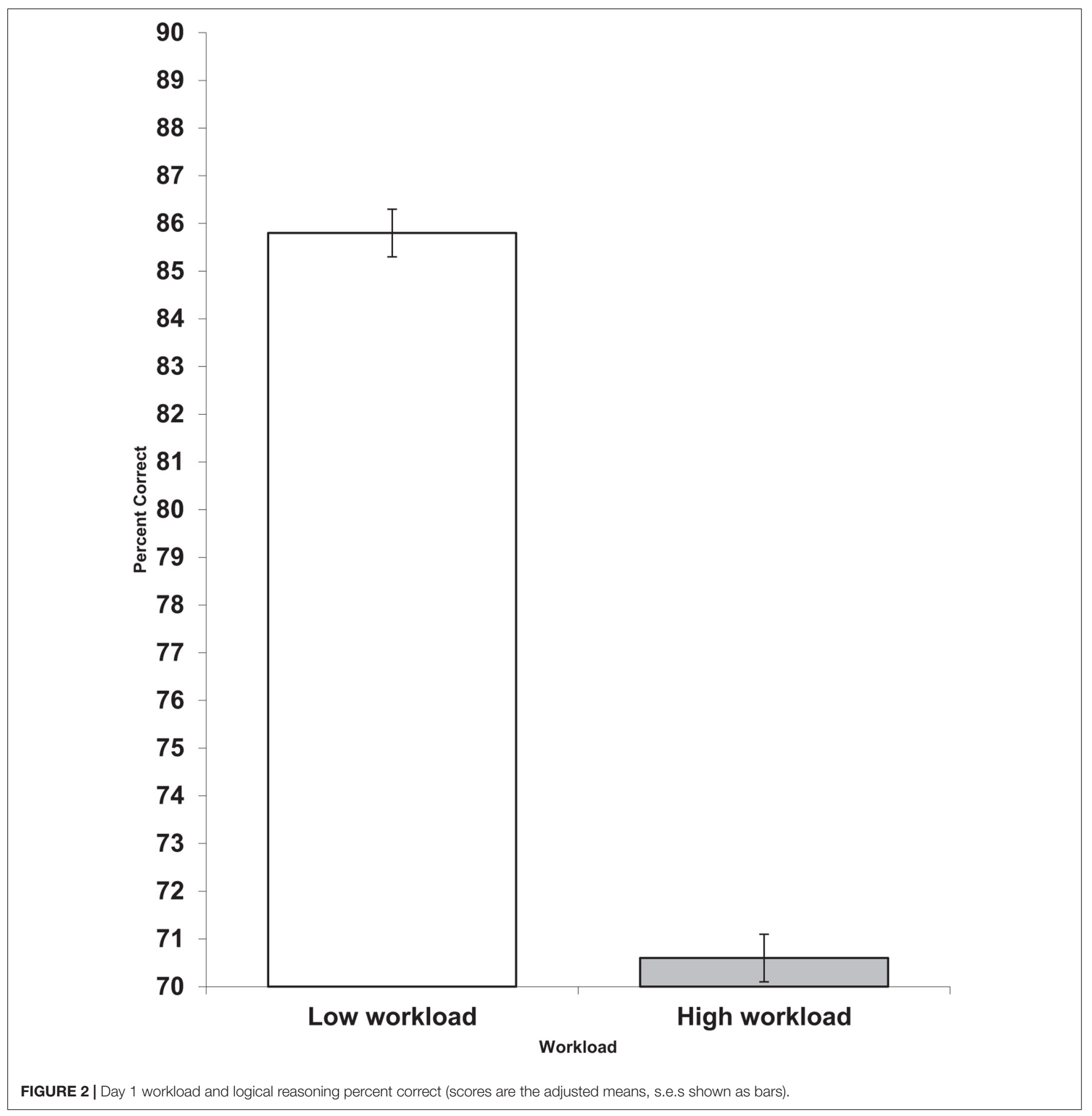

(Fan and Smith, 2017) and those carried out in different transport industries (Feyer and Williamson, 2001; Smith et al., 2006; Smith and Smith, 2017) which found that performance was impaired by fatigue. The effects of fatigue on cognitive performance were found with both high and low workloads. However, there was some evidence of independent effects of workload on performance speed, although such effects were less frequent than those of fatigue. In addition, subjective fatigue increased, and general outcomes got worse at the end of the week, suggesting an effect of cumulative work fatigue on outcomes throughout the working week. This result was very similar to fatigue observed in seafarers, which increased day by day during the tour of duty and continued into leave (Bal et al., 2015).

The main hypothesis of the current study predicted that increased occupational fatigue would lead to performance reduction, including slower RT and lower accuracy rates. Comparable to our student sample study (Fan and Smith, 2017), the results here showed that an increased feeling of fatigue was associated with impaired performance, including decreased accuracy in the visual search task and slower RT in the logical 


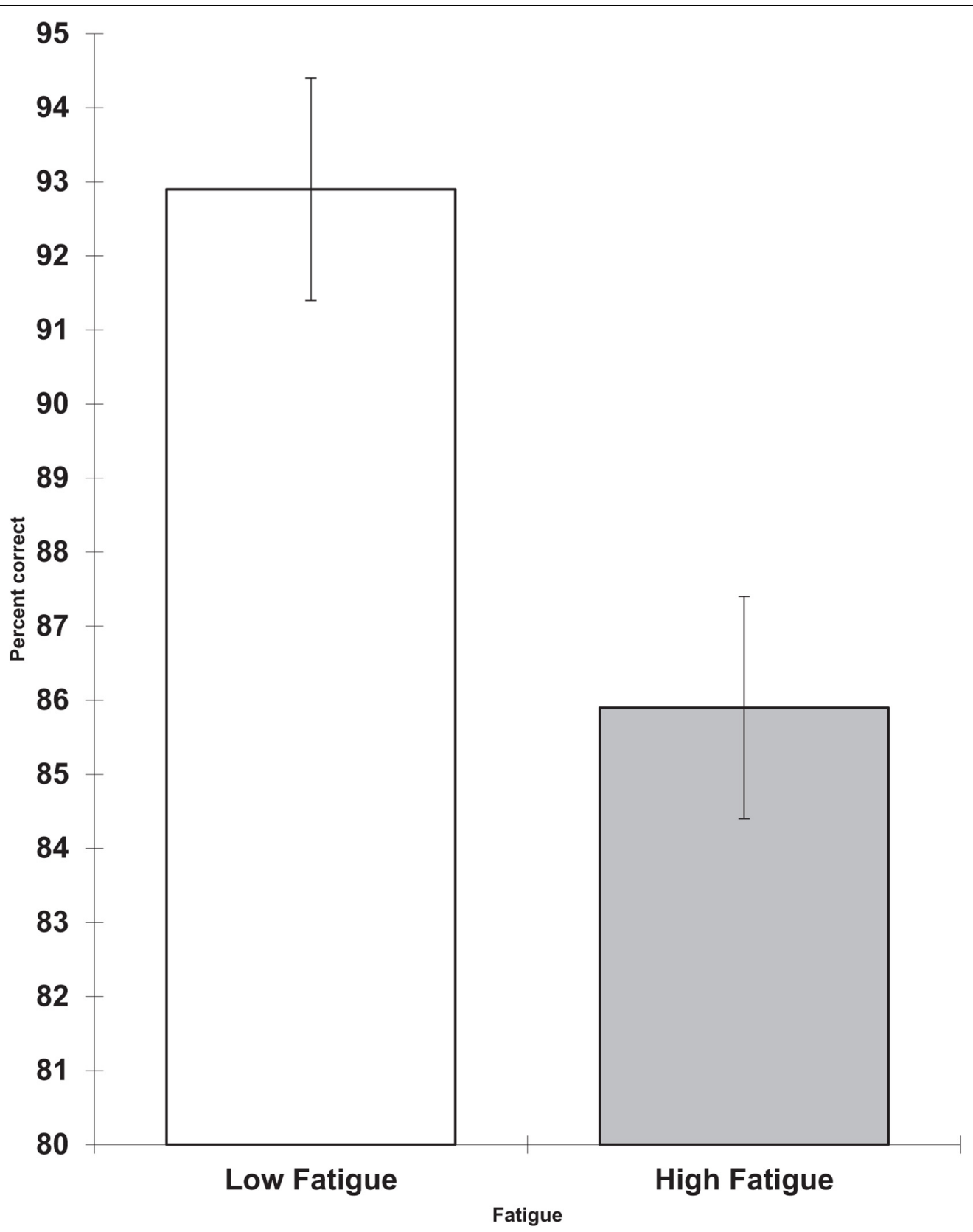

FIGURE 3 | Day 4 fatigue and visual search percent correct (scores are the adjusted means, s.e.s shown as bars).

reasoning task, which supports this hypothesis. The effects of workload were restricted to less accurate performance of the logical reasoning task on the first day.

This study was performed in the United Kingdom and the results were obtained using a United Kingdom sample, and differences in culture (Barlas and Obhi, 2014) were not relevant here. Previous studies have shown that fatigue impaired cognitive performance (e.g., Craig and Cooper, 1992; Beurskens et al., 2000), which was supported by the current study. The results from previous studies also suggest that it could be the increased fatigue, decreased control, and increased automation in the working environment which resulted in the changed sense of agency (e.g., Berberian et al., 2012; Kumar and Srinivasan, 2012, 2013; Moore, 2016; Howard et al., 2016; Di Plinio et al., 2019, 2020). The modern railway industry has increased the level of automation in operating systems and decreased control by operators (Young et al., 2015; Fan and Smith, 2019), and future studies of fatigue in railway staff samples should focus on changes in the sense of agency.

This study investigated the effect of occupational fatigue on cognitive performance in railway staff, and its results provide insight on current practices regarding fatigue management in 


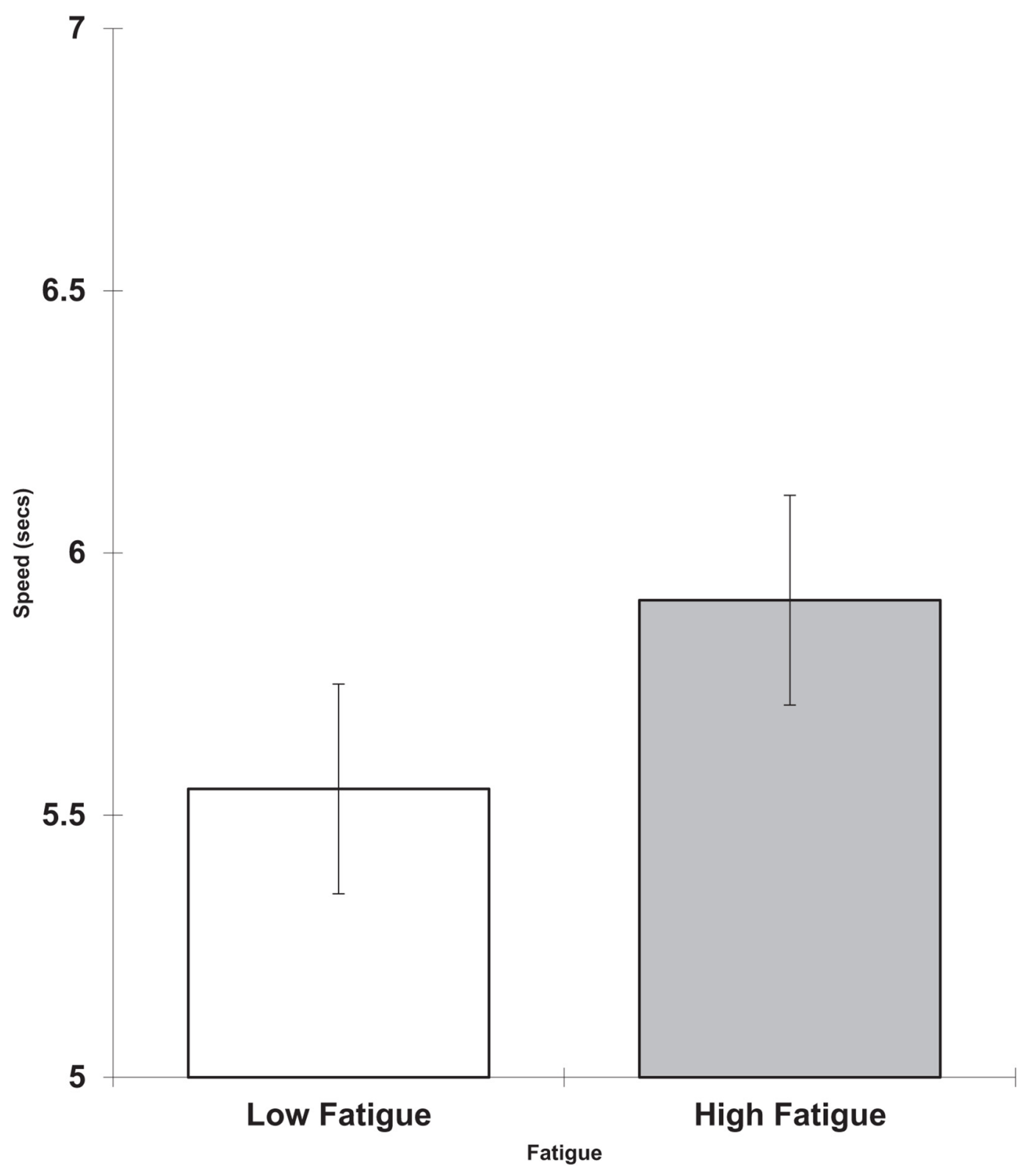

FIGURE 4 | Day 4 fatigue and logical reasoning speed (seconds per item; scores are the adjusted means, s.e.s shown as bars).

the industry. The findings allow us to offer a few suggestions for the railway industry. In general, either organizations or individuals should raise the issue of fatigue and its after-effects, and take action to prevent and manage it and related impaired performance in the workplace. The present research, in line with previous studies (e.g., Dorrian et al., 2011; Fan and Smith, 2017), indicated that workload should be considered as well as fatigue. Considering the nature of jobs in the railway industry, however, it will be not easy to control or reduce the workload, especially with the unpredictability of train problems and unplanned overtime work. Thus, companies and organizations can apply such online fatigue self-assessment and cognitive performance tasks to assess staff fatigue level before and after work. For those with no indication of fatigue, this will not change the normal working behavior of during their duty. For those with fatigue this can be prevented and managed by providing support (e.g., fatigue managing advices or intervention) during times when fatigue is likely to be at a high-risk level. Also, companies may need to improve work patterns and arrange rest times during and after work for recovery from fatigue, which reduces the risk of future fatigue-related performance impairment.

\section{Limitations}

The first sets of limitations are common in diary studies. As a method, the online diary study is less controlled than laboratory experiments, although it has the advantage of assessing the effects 
of fatigue in the context of participants' daily work lives, as well as being able to assess the effect of cumulative fatigue for a longer period of time than in laboratory experiments. One issue is completion of the diary at the correct time. One participant commented that he did not have time to complete the diary immediately after work because he was off very late and caught transport to return home in a hurry. Although this participant completed the post-work diary immediately upon arriving home, his fatigue and performance may have recovered during the commute. Another problem is the completion of the study. Diary studies are also time-consuming, and participants required reminders and encouragement to fully complete the diaries. In this study, it was difficult to recruit participants and have them fully complete all of the four sessions, especially the post-work diary on the last day of the work week. The majority of participants who forgot to fill in the last diary decided to quit the study rather than re-do it. This meant that the major limitation of the present study was the small sample size. The small sample size also meant that it was not possible to consider individual differences, such as job type or the personality of the participants.

\section{Future Research}

The current study was an initial trial of studying the effect of fatigue on performance in a real-life setting. There is a plan to conduct more staff experiments to further investigate the effects of fatigue on performance, as well as intervention experiments. Future research requires better control of online diary data collection. While the online diary is an advanced method for assessing fatigue closely in the context of daily work life, reminder texts or e-mails are needed to ensure that participants fill out each diary on time. The diary could be integrated with the HSE Fatigue and Risk Index (a fatigue prediction tool based on shift patterns currently used in the United Kingdom rail industry) in a future study. Although the job demands variable in this index is usually set at a constant level for all staff, it can be measured through the single-item self-assessment in the diary.

\section{CONCLUSION}

Occupational fatigue is an important issue in the rail industry and it can endanger passenger, staff and train safety. It is also important in jobs which are not safety critical as it can influence the efficiency of the organization and the health and wellbeing of staff. Our previous research has examined this issue in drivers (Evans, 2019), conductors, guards, and engineers (Smith and Smith, 2017). There is now a need to demonstrate the relationship between workload, fatigue, and performance among a wider range of staff of train operating companies. The present study was carried out in the workplace using an online methodology with both subjective and objective measurements. The aim was to examine the relationship between workload, fatigue, and cognitive performance using staff from a train operating company. The "After-Effect" technique was used with online diaries and cognitive performance tasks assessing the fatigue, work experiences, and performance of staff before and after work on the first and fourth days of one working week.
This field study provided evidence for the relationship between work-related fatigue and performance impairment. The findings show the need for future work on predicting fatigue-related performance decrements, and the necessity of providing interventions and support so that the risk to safety can be reduced. The results demonstrated that the objective performance of staff was impaired due to fatigue, shown as decreased accuracy on a visual search task and the logical reasoning task. These findings were in line with those of previous research in other work contexts. Increased fatigue was associated with higher workload, while fatigue before work was also associated with the quality and duration of sleep. Considering it is not easy to control or reduce the workload due to the nature of the jobs, the rail industry could focus instead on improving the guidelines regarding rest to manage fatigue, which would then reduce the risk of work performance impairment. Future research using an online diary should consider recruiting a larger sample and mitigating the risk of absent or incomplete diary entries.

\section{DATA AVAILABILITY STATEMENT}

The raw data supporting the conclusions of this article will be made available by the authors without undue reservation.

\section{ETHICS STATEMENT}

The studies involving human participants were reviewed and approved by School of Psychology Research Ethics Committee at Cardiff University. The patients/participants provided their written informed consent to participate in this study.

\section{AUTHOR CONTRIBUTIONS}

AS formulated the research question, designed the study, and revised the manuscript for important intellectual content. JF conducted the analyses, interpreted the data, and drafted the original manuscript. Both the authors approved the final version for publication and also agreed to be held accountable for all aspects of the work in ensuring that questions related to accuracy and integrity are appropriately investigated and resolved.

\section{ACKNOWLEDGMENTS}

The main content of this paper has previously appeared in JF's Ph.D. thesis, available online in Cardiff University's institutional repository. JF would like to thank AS for his supervision and invaluable guidance in her Ph.D. journey.

\section{SUPPLEMENTARY MATERIAL}

The Supplementary Material for this article can be found online at: https://www.frontiersin.org/articles/10.3389/fpsyg.2020. 558520/full\#supplementary-material 


\section{REFERENCES}

Åhsberg, E., Kecklund, G., Åkerstedt, T., and Gamberale, F. (2000). Shiftwork and different dimensions of fatigue. Int. J. Ind. Ergon. 26, 457-465. doi: 10.1016/ s0169-8141(00)00007-x

Åkerstedt, T. (1988). Sleepiness as a consequence of shift work. Sleep 11, 17-34. doi: $10.1093 /$ sleep/11.1.17

Åkerstedt, T. (1991). "Sleepiness at work: Effects of irregular work hours", in Sleep, Sleepiness and Performance, ed. T. Monk (Oxford: John Wiley \& Sons), 129-152.

Baddeley, A. D. (1968). A $3 \mathrm{~min}$ reasoning test based on grammatical transformation. Psychon. Sci. 10, 341-342. doi: 10.3758/bf03331551

Bal, E., Arslan, O., and Tavacioglu, L. (2015). Prioritization of the causal factors of fatigue in seafarers and measurement of fatigue with the application of the Lactate Test. Saf. Sci. 72, 46-54. doi: 10.1016/j.ssci.2014.08.003

Barker, L. M., and Nussbaum, M. A. (2011). The effects of fatigue on performance in simulated nursing work. Ergonomics 54, 815-829. doi: 10.1080/00140139. 2011.597878

Barlas, Z., and Obhi, S. S. (2014). Cultural background influences implicit but not explicit sense of agency for the production of musical tones. Conscious. Cogn 28, 94-103. doi: 10.1016/j.concog.2014.06.013

Berberian, B., Sarrazin, J. C., Le Blaye, P., and Haggard, P. (2012). Automation technology and sense of control: a window on human agency. PLoS One 7:e34075. doi: 10.1371/journal.pone.0034075

Beurskens, A. J., Bultmann, U., Kant, I., Vercoulen, J. H., Bleijenberg, G., and Swaen, G. M. (2000). Fatigue among working people: validity of a questionnaire measure. Occupat. Environ. Med. 57, 353-357. doi: 10.1136/oem.57. 5.353

Bowler, N., and Gibbon, W. H. (2015). Fatigue and its Contribution to Railway Incidents. Derby: British Rail Accident Investigation Branch (RAIB).

Brice, C., and Smith, A. (2001). The effects of caffeine on simulated driving, subjective alertness and sustained attention. Hum. Psychopharmacol. Clin. Exp. 16, 523-531. doi: 10.1002/hup.327

British Rail Accident Investigation Branch (2008). Derailment of Two Locomotives at East Somerset Junction. Derby: British Rail Accident Investigation Branch.

British Rail Accident Investigation Branch (2010). Uncontrolled Freight Train Run-Back Between Shap and Tebay, Cumbria. Derby: British Rail Accident Investigation Branch.

British Rail Safety and Standards Board (2005). T059 Main Report: Guidelines for the Management and Reduction of Fatigue in Train Drivers. Derby: British Rail Safety and Standards Board.

Broadbent, D. E. (1979). Is a fatigue test now possible? Ergonomics 22, 1277-1290. doi: $10.1080 / 00140137908924702$

Buck, L., and Lamonde, F. (1993). Critical incidents and fatigue among locomotive engineers. Saf. Sci. 16, 1-18. doi: 10.1016/0925-7535(93)90003-V

Cameron, C. (1973). A theory of fatigue. Ergonomics 16, 633-648. doi: 10.1080/ 00140137308924554

Chalder, T., Berelowitz, G., Pawlikowska, T., Watts, L., Wessely, S., Wright, D., et al. (1993). Development of a fatigue scale. J. Psychosom. Res. 37, 147-153. doi: 10.1016/0022-3999(93)90081-p

Chau, N., Bourgkard, E., Bhattacherjee, A., Ravaud, J. F., Choquet, M., Mur, J. M., et al. (2008). Associations of job, living conditions and lifestyle with occupational injury in working population: a population-based study. Int. Arch. Occupat. Environ. Health 81, 379-389. doi: 10.1007/s00420-007-0 223-y

Cheng, Y. H., and Hui-Ning, T. (2019). Train drivers' subjective perceptions of their abilities to perceive and control fatigue. Int. J. Occupat. Saf. Ergon. 26, 20-36. doi: 10.1080/10803548.2019.1568726

Cotrim, T., Carvalhais, J., Neto, C., Teles, J., Noriega, P., and Rebelo, F. (2017). Determinants of sleepiness at work among railway control workers. Appl. Ergon. 58, 293-300. doi: 10.1016/j.apergo.2016.07.006

Craig, A., and Cooper, R. E. (1992). "Symptoms of acute and chronic fatigue," in Handbook of Human Performance, Vol. 3, eds A. P. Smith and D. M. Jones (London: Harcourt Brace Jovanovich), 289-339. doi: 10.1016/b978-012-650353-1.50017-4

Crook, T. H., Kay, G. G., and Larrabee, G. J. (2009). "Computer-based cognitive testing", in Neuropsychological Assessment of Neuropsychiatric and
Neuromedical Disorders, eds I. Grant and K. Adams (United States: Oxford University Press), 84-100.

Di Plinio, S., Arnò, S., Perrucci, M. G., and Ebisch, S. J. H. (2019). Environmental control and psychosis-relevant traits modulate the prospective agency in nonclinical individuals. Conscious. Cogn. 73:102776. doi: 10.1016/j.concog.2019. 102776

Di Plinio, S., Arnò, S., Perrucci, M. G., and Ebisch, S. J. H. (2020). The evolving sense of agency: context recency and quality modulate the interaction between prospective and retrospective processes. Conscious. Cogn. 80:102903. doi: 10. 1016/j.concog.2020.102903

Doherty, M., and Smith, P. M. (2005). Effects of caffeine ingestion on rating of perceived exertion during and after exercise: a meta-analysis. Scand. J. Med. Sci. Sports 15, 69-78. doi: 10.1111/j.1600-0838.2005.00445.x

Dorrian, J., Baulk, S. D., and Dawson, D. (2011). Work hours, workload, sleep and fatigue in Australian Rail Industry employees. Appl. Ergon. 42, 202-209. doi: 10.1016/j.apergo.2010.06.009

Dorrian, J., Hussey, F., and Dawson, D. (2007). Train driving efficiency and safety: examining the cost of fatigue. J. Sleep Res. 16, 1-11. doi: 10.1111/j.1365-2869. 2007.00563.x

Drew, G. C. (1940). An Experimental Study of Mental Fatigue. Report No. 227. Cambridge: Air Ministry, Flying Personnel Research Committee.

Evans, M. S. (2019). The Development and Validity of an Objective Indicator of Fatigue for Frontline Safety Critical Workers. PhD Thesis. Cardiff: Cardiff University.

Fan, J. (2019). An Investigation of Rail Crew Fatigue and Well-Being. [Doctoral dissertation]. Cardiff: Cardiff University.

Fan, J., and Smith, A. P. (2017). "The impact of workload and fatigue on performance," in Proceedings of the International Symposium on Human Mental Workload: Models and Applications, eds L. Longo and M. C. Leva (Cham: Springer), 90-105. doi: 10.1007/978-3-319-61061-0_6

Fan, J., and Smith, A. P. (2018). A preliminary review of fatigue among rail staff. Front. Psychol. 9:634. doi: 10.3389/fpsyg.2018.00634

Fan, J., and Smith, A. P. (2019). "Mental workload and other causes of different types of fatigue in rail staff," in Proceedings of the International Symposium on Human Mental Workload: Models and Applications, eds L. Longo and M. C. Leva (Cham: Springer), 147-159. doi: 10.1007/978-3-030-14273-5 9

Ferguson, S. A., Lamond, N., Kandelaars, K., Jay, S. M., and Dawson, D. (2008). The impact of short, irregular sleep opportunities at sea on the alertness of marine pilots working extended hours. Chronobiol. Int. 25, 399-411. doi: 10. 1080/07420520802106819

Feyer, A. M., and Williamson, A. M. (2001). "Broadening our view of effective solutions to commercial driver fatigue," in Stress, Workload and Fatigue, eds P. A. Hancock and P. A. Desmond (New York, NY: Lawrence Erlbaum), 550-565.

Filtness, A. J., and Naweed, A. (2017). Causes, consequences and countermeasures to driver fatigue in the rail industry: the train driver perspective. Appl. Ergon. 60, 12-21. doi: 10.1016/j.apergo.2016.10.009

Harma, M., Sallinen, M., Ranta, R., Mutanen, P., and Müller, K. (2002). The effect of an irregular shift system on sleepiness at work in train drivers and railway traffic controllers. J. Sleep Res. 11, 141-151. doi: 10.1046/j.1365-2869.2002.00294.x

Harma, M., Suvanto, S., Popkin, S., Pulli, K., Mulder, M., and Hirvonen, K. (1998). A dose-response study of total sleep time and the ability to maintain wakefulness. J. Sleep Res. 7, 167-174. doi: 10.1046/j.1365-2869.1998.00115.x

Hockey, G. R. J., and Earle, F. (2006). Control over the scheduling of simulated office work reduces the impact of workload on mental fatigue and task performance. J. Exp. Psychol. Appl. 12, 50-65. doi: 10.1037/1076-898x.12.1.50

Howard, E. E., Edwards, S. G., and Bayliss, A. P. (2016). Physical and mental effort disrupts the implicit sense of agency. Cognition 157, 114-125. doi: 10.1016/j. cognition.2016.08.018

Kim, E., Lovera, M. J., Schaben, L., Bourdette, D., and Whitham, R. (2010). Novel method for measurement of fatigue in multiple sclerosis: real-time digital fatigue score. J. Rehabilit. Res. Dev. 47, 477-484. doi: 10.1682/jrrd.2009.09. 0151

Kishida, K. (1991). "Workload of workers in supermarkets," in Towards Human Work: Solutions to Problems in Occupational Health and Safety, eds M. Kmashiro and E. D. Megaw (London: Taylor and Francis), 269-279. 
Kogi, K., Saito, Y., and Mitsuhashi, T. (1970). Validity of three components of subjective fatigue feelings. J. Sci. Lab. 46, 251-270.

Krueger, G. P. (1989). Sustained work, fatigue, sleep loss and performance: a review of the issues. Work Stress 3, 129-141. doi: 10.1080/02678378908 256939

Kumar, D., and Srinivasan, N. (2012). Hierarchical event-control and subjective experience of agency. Front. Psychol. 3:410. doi: 10.3389/fpsyg.2012.00410

Kumar, D., and Srinivasan, N. (2013). "Hierarchical control and sense of agency: differential effects of control on implicit and explicit measures of agency," in Proceedings of the Annual Meeting of the Cognitive Science Society, Berlin.

Lamond, N., and Dawson, D. (1999). Quantifying the performance impairment associated with fatigue. J. Sleep Res. 8, 255-262. doi: 10.1046/j.1365-2869.1999. 00167.x

Moore, J. W. (2016). What is the sense of agency and why does it matter? Front. Psychol. 7:1272. doi: 10.3389/fpsyg.2016.01272

Parkes, K. R. (1995). The effects of objective workload on cognitive performance in a field setting: a two-period cross-over trial. Appl. Cogn. Psychol. 9, S153-S171. doi: 10.1002/acp.2350090710

Smith, A. (2002). Effects of caffeine on human behavior. Food Chem. Toxicol. 40, 1243-1255. doi: 10.1016/s0278-6915(02)00096-0

Smith, A., Thomas, M., and Whitney, H. (2000). Effects of upper respiratory tract illnesses on mood and performance over the working day. Ergonomics 43, 752-763. doi: 10.1080/0014013004 04724
Smith, A. P., Allen, P. H., and Wadsworth, E. J. K. (2006). Seafarer Fatigue: The Cardiff Research Programme. Cardiff: Centre for Occupational and Health Psychology.

Smith, A. P., and Smith, H. N. (2017). "Workload, fatigue and performance in the rail industry," in Human Mental Workload: Models and Applications. H-WORKLOAD 2017. Communications in Computer and Information Science, Vol. 726, eds L. Longo and M. C. Leva (Cham: Springer), 251-263. doi: 10.1007/ 978-3-319-61061-0_17

Ugajin, H. (1999). Human factors approach to railway safety. Q. Rep. RTRI 40, 5-8. doi: $10.2219 /$ rtriqr.40.5

Young, M. S., Brookhuis, K. A., Wickens, C. D., and Hancock, P. A. (2015). State of science: mental workload in ergonomics. Ergonomics 58, 1-17. doi: 10.1080/ 00140139.2014 .956151

Conflict of Interest: The authors declare that the research was conducted in the absence of any commercial or financial relationships that could be construed as a potential conflict of interest.

Copyright $(2020$ Fan and Smith. This is an open-access article distributed under the terms of the Creative Commons Attribution License (CC BY). The use, distribution or reproduction in other forums is permitted, provided the original author(s) and the copyright owner(s) are credited and that the original publication in this journal is cited, in accordance with accepted academic practice. No use, distribution or reproduction is permitted which does not comply with these terms. 